\title{
Epifanía y poema en prosa: el Livro do Desassossego de Fernando Pessoa/Bernardo \\ Soares
}

\author{
Raúl Romero \\ René P. Garay \\ The City University of New York
}

Tenho gasto a [vida] fazendo versos em prosa às sensações intransmissíveis com que torno meu o universo incógnito.

Pessoa/Soares. Livro do Desassossego, p. 210.

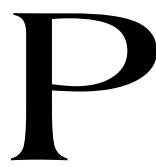

oema en prosa o prosa poética son rótulos que varían, pero que se apoyan - a su vez - en una comodidad estética. No siempre la prosa de carácter artístico alcanza categoría poética, pues aquella puede lograrse solamente por medio de simples elementos formales y decorativos y hasta cierto punto artificiosos. Esta característica la hace muchas veces insoportable a la sensibilidad cibernética y visual del mundo actual. El poema en prosa es un término a veces arbitrario, inconsistente y por veces ilusorio que se concentra en la exigencia básica de la brevedad denotada perspicazmente como un momento de iluminación, y que se observa irrefutablemente en esa epiphaneia de revelación íntima que inundaba los textos de creadores tan disímiles como Santa Teresa y James Joyce.

El poema en prosa es una manifestación de este momento individual de lirismo que no respeta las formas tradicionales y convencionales del verso. El poema en prosa es subversivo por naturaleza. Es irreverente, iconoclasta y es, sobretodo, una experiencia profundamente personal. No acepta las fronteras represivas de la gramática tradicional, juega con la retórica y se divierte con los temas que muchas veces no pueden ser descubiertos en una primera lectura. 
Textos narrativos de carácter poético hay muchos, por ejemplo, $\bar{A}$ la recherche du temps perdu de Proust, Iracema de José de Alencar, Eurico, o presbitero de Alexandre Herculano, Stephen Hero (esbozo para Portrait of an Artist as a Young Man) y Giacomo Joyce de James Joyce , por mencionar los casos más evidentes y en cierto modo "populares" y hay esos otros textos a los cuales se les denomina poesía pura, pero también tenemos ese híbrido que se sitúa entre estos textos narrativos y esa poesía pura que se pueden considerar de forma total como poema en prosa. El poema en prosa podría definirse como una visión ilusoria y sutil de una realidad, el primer adjetivo sirve para caracterizar el contenido, su filosofía de estilo, su filosofía temática (ontología) y en cierto modo su ideología literaria puesto que entre aquellos que se dedican al poema en prosa se exige un estado de disponibilidad, una entrega, una sublimación donde todas las percepciones son subjetivas. El poema en prosa es todo alma, es una ilusión que escapa de la dura realidad imposible de ser descrita de una forma narrativa convencional y que sólo a través de los mecanismos ambiguos de la poesía podría describirse. El otro objetivo, el de la sutileza, sirve para marcar las cualidades formales de este género, su síntesis, su brevedad y sus juegos retóricos. El poema en prosa, en ese aspecto, es comparable al soneto, posee una economía de elementos con el objetivo de alcanzar un fin supremo. Sin embargo, no todos los poemas en prosa tienen este carácter espiritualista de la poesía simbolista, muchos poemas en prosa recurren como parte de su estrategia ideológica a temas y propuestas más mundanos, más abarcadores, polifonías, como en el caso de la greguería de Gómez de la Serna donde el poeta afirma que "el soneto es el chaleco de seda de la poesía." En la civilización occidental son dos franceses los que pusieron de moda el poema en prosa: Aloysius Bertrand con su Gaspard de la Nuit escrito en 1836 y publicado póstumamente y Charles Baudelaire con su Spleen de Paris. Otros ejemplos fundamentales incluyen las Memorable fancies de William Blake, los Cantos de Maldoror del famoso conde Lautreamont, los poemas en prosa de Stéphane Mallarmé, De Profundis de Oscar Wilde y Edgar Allan Poe con su cosmogónica Eureka.

Entonces ¿¿cuál es el enigma de este subgénero literario? ¿Cuál sería la definición más exacta? La más corta es casi tautológica. Es un poema escrito en prosa y no en verso, puede parecer un párrafo o un cuento corto fragmentado. El poema en prosa actúa como un poema en el sentido de que se vale de las estrategias y tácticas de la poesía, de la misma manera 
que el verso libre lo hace con la métrica y la rima, pero éste lo hace con la línea como unidad de composición. El subgénero se vale de los medios e instrumentos de la prosa con los objetivos de la poesía, entendiéndosecomo lo hace Pessoa/Soares - que "a gramática é um instrumento e não uma lei" (Livro do Desassossego, 113).

Se podría decir que el poema en prosa es poesía que esconde su verdadera naturaleza. En este, el poeta puede apropiarse de modelos como un artículo periodístico, un memorandum, una lista, una parábola, un discurso, o un diálogo. Es una forma poética con un uso más vernáculo que, según algunos críticos, reproduce la relación de adversario entre el discurso de la literatura burguesa y el de clase obrera (Lehman 13) que va eliminando el poder absoluto de las estructuras líricas de la clase letrada. Pero la única generalización segura que se puede hacer sobre el poema en prosa es que se resiste a una generalización ya que es una forma híbrida, una anomalía, una paradoja o, según Michael Riffaterre, un oxímoron, i.e., "el género literario con un oxímoron por nombre".

El poema en prosa ofrece la posibilidad de escapar de las invisibles cadenas del superego, ofrece la alternativa de huir del reino opresivo de la métrica tradicional, como Charles Baudelaire lo hace en "petits poèmes en prose", donde se deshacen las fronteras genéricas del discurso tradicional. Se puede decir que es un género que nace de una rebelión contra el canon, pero, que al paso del tiempo, se ha convertido en un sistema canónico. El poema en prosa es un antigénero, oximorónico por excelencia y totalmente penetrado por el concepto curiosamente subversivo de epifanía. El estilo de un artista es determinado por la forma en que usa los instrumentos de la escritura. En muchos casos estos instrumentos no son originales o nuevos; sin embargo, sus usos pueden serlo y es esta originalidad la que los hace únicos. Estos instrumentos le dan al artista una identidad estilística peculiar. Separan cada esfuerzo creativo y al mismo tiempo le ofrecen un sentido de unidad.

Fernando Pessoa en su intensa preocupación con la esencia del ser intentó descubrirla a través de ese peculiar mecanismo literario conocido como la epifanía. La idea de la epifanía no es nueva, pero se ha usado de una manera extremadamente frecuente en la literatura moderna. La epifanía (i.e., epiphaneia) en el mundo occidental se remonta, en sus orígenes, a la tradición cristiana: la experiencia de Pablo en su camino a Damasco, las visiones de Dios de los profetas, los encuentros de los místicos españoles y las numerosas experiencias de conversión en la 
historia de la hegemonía cristiana (e.g., in hoc signo vinces de Constantino I, el Grande). Todos estos momentos de iluminación o revelación son una experiencia mística religiosa que tiene mucho en común con la epifanía literaria, especialmente su aspecto trascendental. En ambos casos tenemos unos momentos individuales, repentinos, cortos, intensos, los cuales producen una nueva conciencia que puede ser dolorosa o excitante. Sin embargo, las antiguas revelaciones son religiosas por naturaleza y poseen una negación del ser, lo que las hace tremendamente impersonales.

La epifanía literaria, en cambio, es intensamente personal y por ende potencialmente trivial. Tiene una esencia generalizadora y produce una concientización separada del ser, normalmente un vis-à-vis entre la vida y el mundo circundante. Este cambio de focalización quizá se deba a la pérdida de fe en el mundo moderno, en el cual se sustituye la religión como fuente de conocimiento por la experiencia del individuo y su confrontación con la vida cotidiana. El vivir es mucho más importante ya que la vida es una consecución de experiencias, las cuales tienen significación para un individuo y que aparentemente son triviales para otros, las banalidades adquieren importancia, la respuesta personal a estas trivialidades se convierte en una fuente potencial para una conciencia instantánea de la esencia del ser. La experiencia de iluminación es más que una experiencia mística ya que es una experiencia individual mucho más cercana a la epifanía literaria que a la revelación mística de la experiencia religiosa. La preocupación filosófica del hombre moderno con la naturaleza y el sentido de la experiencia son reflejadas en la literatura.

En el uso de la epifanía literaria existe una explicación más técnica que filosófica, la cual explica el por qué del incremento de su uso por escritores modernos; que es la invasión de la prosa de ficción por los recursos y procedimientos de la poesía. Las preocupaciones filosóficas de los escritores existencialistas se combinan con las técnicas de los poetas y de ahí emerge una nueva forma de prosa ficcional; una en la cual la compleja naturaleza de la existencia humana es sutilmente explorada a través de técnicas que se concentran en la internalización de la realidad externa y su subsiguiente externalización en la forma de una realidad enteramente nueva. La destilación de ambas en un intento de reflejar esa naturaleza del ser. También los escritores muestran un interés en objetos aparentemente insignificantes y en eventos banales - y no de la manera en que los autores realistas y psicológicos hicieron en la prosa de ficción decimonónica - ya que sus preocupaciones son completamente 
diferentes, y es aquí donde básicamente radica la importancia de la epifanía como técnica literaria central en la ficción moderna. James Joyce usa el término epiphany por primera vez para referirse a un tipo específico de género prosístico que se define en Stephen Hero.

Nuestro poeta en cuestión, Fernando Pessoa, híbrido por naturaleza, multipersonal y, si nos aventuramos y somos-a su vezconsecuentes con la experiencia heteronímica del escritor, multiepifánico. Es un autor para el cual no existen absolutismos literarios, ni clasificaciones herméticas que dividirían prosa, lírica o ensayística ya que el sentimiento poético impregna todo lo que escribió. El sentido poético es inherente a la escrita pessoana, su obra es capaz de comunicar, explicar, argumentar y analizar en una forma repleta de poesía y este espíritu literario es transmitido-sin discriminar - a todos los heterónimos, desde los más políticos hasta los más líricos.

El sentimiento epifánico invade a cada una de estas extensiones de la persona Pessoa, en cada uno de sus heterónimos existe una inaudita manifestación espiritual, una liberación dramática del yo, la obra poética pessoana posee una extraordinaria significación estética y espiritual y cada palabra escrita ya sea por Caeiro, Soares, o Pessoa ortónimo poseen esta trascendencia temática que redefine el concepto estático de géneros literarios. El carácter epifánico de la obra del escritor portugués posee una excéntrica armonía que se relaciona con la meditación y le da un rasgo visionario aún cuando escribe sobre temas mundanos, vulgares o cotidianos. El caso del Fernando Pessoa travestido en el semi-heterónimo Bernardo Soares, es el más notable desde el punto de vista epifánico, en el Livro do Desassossego el poeta-narrador-cronista-filósofo expresa sus ideas de una manera que la hacen parecer como una revelación divina. Como se dijo anteriormente esto no tiene específicamente que ver con las ideas expresadas en el texto de Soares sino con la opción literaria elegida por el autor, la prosa de carácter poético, lo que le otorga una vez más a este sub-género una identidad completamente epifánica.

Adelto Gonçalves en su ensayo "Prosa Poética e Poema em Prosa no Livro do Desassossego", nos explica esta habilidad pessoana. El crítico brasileño analiza varios fragmentos del texto escrito por el semiheterónimo Bernardo Soares. Gonçalves asevera que en el fragmento donde Pessoa "conoce" a su semi-heterónimo utiliza equilibradamente el lenguaje simbólico y el subjetivo, como se puede observar a continuación: 
Um dia houve um acontecimento na rua, por baixo das janellas - uma scena de pugilato entre dois indivíduos. Os que estavam na sobreloja correram às janellas, e eu também, e também o indivíduo de quem fallo. Troquei com elle uma phrase casual, e elle respondeu no mesmo tom. A sua voz era baça e trêmula, como a das creaturas que não esperam nada, porque é perfeitamente inútil esperar. Mas era porventura absurdo dar esse relevo ao meu collega vespertino de restaurante.

En este contexto, es interesante la propuesta de Gonçalves quien asegura que

Ha ritmo nas palavras, o que é uma condição inata do poema, mas não essencial à prosa. Como prosador, aqui o autor busca a coerência e a claridade conceitual e resiste à corrente rítmica que fatalmente tende a se manifestar em imagens e não em conceitos, como no trecho em que volta à realidade ao dizer: 'Mas era porventura absurdo dar esse relevo ao meu collega vespertino de restaurante'.

En todo caso, lo poético domina el texto de Fernando Pessoa borrando las barreras entre prosa pura y prosa de carácter lírico que en la definición de Octavio Paz es poesía en estado amorfo. Para Gonçalves este fragmento está lejos de ser un poema en prosa porque es: uma expressão do 'nãoeu': quem e o escreve está dirigido para for a do seu mundo, observando a realidade exterior. Mas a sua ação é interna, passa-se na consciência da personagem, como numa ficção instrospectiva. O escritor está para o 'nãoeu', descrevendo com pormenores o momento de su primeiro encontro com alguém que se supõe tenha se tornado seu amigo. O seu tempo é psicológico, interior. E o espaço não assume maior importância como cenário. Aqui há um arremedo de enredo, uma breve intriga ficcional, e uma outra personagem além de quem escreve. São esse ser vivo e as coisas ao redor dele e do autor que constituem a massa de sua prosa poética. (34)

Para muchos, un poema en prosa es un sinnúmero de pequeñas piezas líricas en las que prepondera el uso del "yo", o sea: el poeta volviéndose para dentro de sí mismo o, recordando las palabras de Massaud Moisés, el poeta haciéndose al mismo tiempo espectáculo y espectador. Las ideas de Gonçalves y Moisés son constatables en el siguiente fragmento del Livro do Desassossego: 
Eu nunca fiz senão sonhar. Tem sido esse, e esse apenas, o sentido da minha vida. Nunca tive outra preocupação verdadeira senão a minha vida interior. As maiores dores de minha vida esbatem-de-me quando, abrindo a janella para dentro de mim, pude esquecer-me na visão do seu movimento.

Gonçalves inclusive sugiere que éste pudiera dividirse en segmentos versificados a semejanza de tantos versos libres escritos por el poeta, lo que hoy ya es una realidad si tomamos el ejemplo de otro fragmento llamado "Nuvens" en su variación versificada en una página cibernética donde los creadores de la misma "violan" o re-interpretan la escritura pessoana, despojándola de su naturaleza prosística para ofrecerle una total identidad poética, convirtiéndolo en un largo poema:

Libro del desasosiego (fragmento)

Nubes... Hoy tengo conciencia del cielo, pues hace días que no lo miro pero lo siento, viviendo en la ciudad y no en la naturaleza que la incluye. Nubes... Son ellas hoy la principal realidad, y me preocupan como si el velarse del cielo fuese uno de los grandes peligros de mi destino. Nubes... Pasan desde la barra hacia el Castillo, de Occidente a Oriente, en un tumulto disperso y desnudo, blanco a veces, se ven desharrapadas en la vanguardia de no sé qué; medio-negro otras, si, más lentas, tar- dan en ser barridas por el viento audible; negras de un blanco sucio, si, como si quisiesen quedarse, ennegrecen más de la venida que de la sombra lo que las calles abren de falso espacio entre las líneas cerradas de las casas.

Nubes... Existo sin saberlo y moriré, sin quererlo. Soy el intervalo entre lo que soy y lo que no soy, entre el sueño y lo que la vida ha hecho de mí, la medida abstracta y carnal entre cosas que no son nada, siendo yo también nada. Nubes... iQué desasosiego si siento, qué desconsuelo si pienso, qué inutilidad si quiero! Nubes... Están pasando siempre, unas muy grandes, pareciendo, porque las casas no dejan ver si son menos grandes de lo que parecen, que van a ocupar todo el cielo; otras de tamaño incierto, que pueden ser dos juntas o una que va a par- tirse en dos, sin sentido en el aire alto contra el cielo cansado; otras aún, pequeñas, que parecen juguetes de poderosas cosas, bolas irregulares de un juego absurdo, sólo hacia un lado, en un gran aislamiento, frías. Nubes... Me interrogo y me desconozco. Nada he hecho de útil ni haré de justificable. He gastado la parte de la vida que no perdí en interceptar confusamente cosa ninguna, haciendo versos en prosa a las sensaciones intransmisibles con que hago mío el universo desconocido. 
Estoy harto de mí, objetiva y subjetiva- mente. Estoy harto de todo, y del todo de todo. Nubes... Son todo, desarreglos de lo alto, cosas hoy sólo ellas reales entre la tierra nula y el cielo que no existe; harapos indescriptibles del tedio que les supongo; niebla condensada en amenazas de color ausente; algodones en rama sucios de un hospital sin paredes. Nubes... Son como yo, un pasar desfigurado entre el cielo y la tierra, al sabor de un impulso invisible, tronando o no tronando, alegrando blancas u obscureciendo negras, ficciones del intervalo y del error, lejos del ruido de la tierra y sin tener el silencio del cielo. Nubes... Siguen pasando, siguen siempre pasando, pasarán siempre siguiendo, en un enrollamiento discontinuo de madejas empañadas, en un alargamiento difuso de falso cielo deshecho.

15-9-1931

No hay dudas para el autor que fue Fernando Pessoa - o los autores que fue Fernando Pessoa - que los géneros "não se separam com tanta facilidade íntima" (Gonçalves 25). Esta aseveración de Pessoa define su ideología literaria, ideología que no posee fronteras ni límites, y si de alguna manera se pueden imponer barreras, éstas sólo existen en el descubrimiento de la experiencia personal y poética, como si las palabras fueran una extensión mecánica del yo. Pessoa se alimenta de las dualidades, de la hibridez, del yo propio, desprovisto de una seducción prefabricada. La estética, la lírica, la musicalidad, la rima, y el arrebato de las metáforas disfrutan de intensidad poética ya que el texto escrito-ya seaen forma de verso o prosa, en forma de artículo periodístico o ensayo, es monopolizado por la belleza profana y sagrada de la poesía; porque como en la pintura o en la música, la belleza de un paisaje pictórico o un fragmento musical es, por naturaleza, poética y es, por fuerza, una experiencia personal.

\section{Bibliografia}

AZEVEDO, Maria Teresa Schiappa de. "Uma Réplica a Safo em Fernando Pessoa" in ACTAS do I Congresso Internacional de Estudos Pessoanos. Porto: Brasília Editora, 1978: 557-574.

BERNARD, Suzanne. Le Poème en prose de Baudelaire jusqu'à nos jours. Paris: Librairie Nizet, 1959.

CULLER, Jonathan. Structuralist Poetics: Structuralism, Linguistics and the Study of Literature. London: Routledge and Kegan Paul, 1975. 
DELVILLE, Michel. The American Prose Poem. Poetic Form and the Boundaries of Genre. Gainesville: University Presses of Florida, 1998.

DUBOIS, Page. Sappho is Burning. Chicago: University of Chicago Press, 1995. GONÇAlVES, Adelto. Fernando Pessoa: a Voz de Deus. Santos: Editora da Universidade Santa Cecília, 1997.

GUILLÉN, Claudio. "Poetics as System." Comparative Literature 22:3 (1970): 193-222.

JOYCE, James. Poems and Shorter Writings, ed. Richard Ellman, A. Walton Litz, and John Whittier-Ferguson. London: Faber, 1991.

JOYCE, James. Stephen Hero. London: New Directions, 1944.

LEHMAN, David, ed. Great American Prose Poems. From Poe to the Present. New York: Scribner Poetry, 2003.

MONROE, Jonathan. A Poverty of Objects. The Prose Poem and the Politics of Genre. Ithaca, N.Y.: Cornell UP, 1987.

MOISÉS, Massaud. Dicionário de Termos Literários. São Paulo: Editora Cultrix, 1982.

MURPHY, Margueritte. A Tradition of Subversion: The Prose Poem in English from Wilde to Ashbery. Amherst: University of Massachusetts Press, 1992.

PADRÃO, Maria da Glória. "Na Floresta do Alheamento: Pensar o Texto Hoje" in ACTAS do I Congresso Internacional de Estudos Pessoanos. Porto: Brasília Editora, 1978: 517-524.

PAZ, Octavio. El arco y la lira. El poema. La revelación poética. Poesía e Historia. México: Fondo de Cultura Económica, 1967.

PESSOA, Fernando. Livro do Desassossego. Composto por Bernardo Soares, Ajudante de Guarda-Livros na Cidade de Lisboa. Richard Zenith, ed. São Paulo: Companhia de Letras, 1999.

PESSOA, Fernando. "Textos de Crítica e de Intervenção" in Obras Completas de Fernando Pessoa. Lisboa: Edições Ática, 1993.

RIFFATERE, Michael. "On the Prose Poem's Formal Features" in The Prose Poem in France. Mary Ann Caws and Hermine Riffaterre, eds. New York: Columbia UP, 1983: 117-132.

RODRIGUES, Ângela Maria Varela Mirando. O Poema em Prosa na Literatura Portuguesa. Dissertação para Licenciatura. Lisboa: Universidade de Lisboa, 1974. 
SOARES, Bernardo. Libro del desasosiego (fragmento). Retrieved on 20 May 2004. http://www.geocities.com/Paris/Cafe/2928/lit/pessoa/pessoa3.html.

UTRERA TORREMOCHA, María Victoria. Teoría del poema en prosa. Sevilla: Universidad de Sevilla. Secretariado de Publicaciones, 1999.

\section{Resumo}

El tema de este ensayo es el poema en prosa como categoría estética presente en la obra de Fernando Pessoa. Se pretende analizar su carácter subversivo e híbrido como género literario así como su ideología artística en el Livro do Desassossego del semi-heterónimo, Bernardo Soares. Más allá de esta problemática que nos presenta la nomenclatura de géneros literarios, se intentará también subrayar la importancia del momento lírico que caracterizó la escrita modernista por medio de la "epifanía", especialmente su intertextualidad con los escritores de prosas escritas como poema.

\section{Abstract}

The topic of this paper is the prose poem as an esthetic category in the work of Fernando Pessoa. It will address its subversive and hybrid aspects as a literary genre as well as its artistic ideology in the Book of Disquietude, written by the fictitous (i.e., semi-heteronymic) Bernardo Soares. In addition to the problems pertaining to definitions of literary genres, an emphasis will be placed on the lyrical mode of modernist literature as witnessed in the so-called "epiphany," especially its intertextuality with writers of the type of prose conceived as a poem. 